\title{
TENTOONSTELLING: ANTIEKE BRONZEN; MEESTERWERKEN UIT HET SHANGHAI MUSEUM
}

Vanaf 2 februari presenteert het Groninger Museum een tentoonstelling van bronzen uit het oude China. De meeste van deze objecten zijn pas recent gevonden nadat ze vele eeuwen aan het oog ontrokken zijn geweest, omdat ze in graftombes zijn meegegeven, of omdat ze in ondergrondse bergplaatsen waren verstopt. De collectie van het Shanghai Museum wordt nauwelijks ergens geëvenaard. Voor het eerst is nu een deel van deze beroemde verzameling in Nederland te zien.

De vaten en klokken die voor deze presentatie zijn geselecteerd, zijn 2000 tot 3800 jaar geleden gegoten. Deze periode wordt aangeduid als de Bronstijd, een etiket dat eigenlijk niet passend is, want in deze tijd werd niet alleen brons verwerkt, maar ook andere materialen zoals jade, ivoor, turkoois, lak en zijde. De term Bronstijd is dan ook een vrij recent begrip. Traditioneel spraken Chinese historici van 'de Oudheid', of de 'Drie Tijdperken', waarmee werd verwezen naar de drie opeenvolgende rijken: het legendarische Xia-rijk en de twee daaropvolgende koninkrijken, Shang en Zhou.

Of de Xia, die tot ongeveer 1700 v.Chr. aan de macht zouden zijn geweest, werkelijk hebben bestaan wordt tegenwoordig door sommige wetenschappers betwist. Het bestaan van de volgende twee koninkrijken daarentegen is door bronnen en materiële vondsten bevestigd. Zo zijn de namen van sommige Shang- en bijna alle Zhou-koningen en hun achtereenvolgende bewindsperiodes bekend. De Shang regeerden eeuwenlang over een groot deel van Noord-China rond de huidige stad Zhengzhou, tot ze in 1045 v.Chr. werden verslagen door de Zhou. De heerschappij van de Zhou, waarvan het zwaartepunt aanvankelijk in het westen en daarna in het oosten lag, duurde meer dan acht eeuwen lang.

Op enkele uitzonderingen na zijn alle objecten in de tentoonstelling ontstaan in de Shang- of de Zhou-tijd. Ze zijn vervaardigd in brons, een legering van koper en tin. Meestal is hier nog een hoeveelheid lood aan toegevoegd om de vloeibaarheid van het gesmolten metaal tijdens het gieten te verbeteren. Vandaag de dag vertonen de meeste oude bronzen het groene patina van koperoxidatie, maar vlak na hun vervaardiging glansden ze met de rijke gloed van koper. In uitzonderlijke gevallen hebben vaten hun oorspronkelijke 'gouden' kleur behouden.

De mensen uit de Bronstijd - net als de verzamelaars vele eeuwen later noemden brons het 'voorspoedbrengende metaal' (jijin). Evenals goud in vele westerse culturen, heeft brons lange tijd een uitstraling gehad van magie en macht. Trouwe dienst werd tijdens de Shang, Zhou en later ook andere regimes, beloond met schenkingen van land, slaven en hoeveelheden brons. Wie zo'n gave van metaal ontving, mocht dit tot vaten laten gieten ter herdenking van zijn roemrijke daden. 

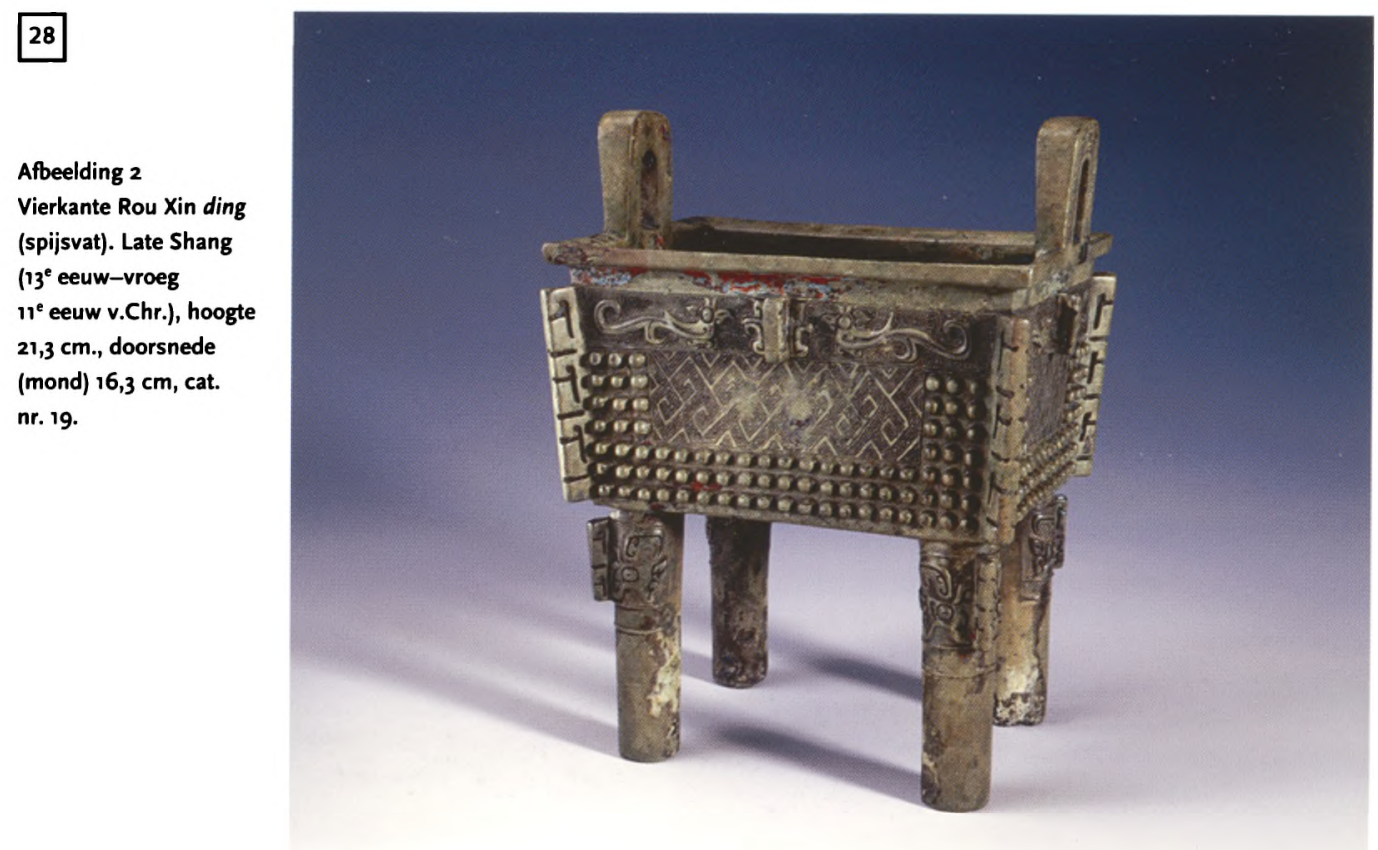

\section{Unieke Gietvormen}

Voorwerpen van brons werden gegoten in gietvormen van keramiek. Het principe van het gebruik van een keramische gietvorm of mal is vrij eenvoudig, maar het was een zeer arbeidsintensieve methode die een grote precisie vereiste. De eerste stap in de productie van een bronzen vat was het maken van een massief kleimodel met daarop de gekozen decors. Op basis daarvan werd een mal voor de buitenwand vervaardigd. De mal voor de binnenwand werd gevormd door het kleimodel zelf, waarvan een laagje werd afgeschraapt zodat hij in de buitenmal paste. In de smalle ruimte tussen die twee vormen werd dan het gesmolten metaal gegoten dat vervolgens uithardde in de vorm van het bronzen vat. Dit alles moest met grote voorzichtigheid gebeuren, want als deze ruimte niet overal even groot was bijvoorbeeld wanneer de binnen- en de buitenmal elkaar raakten - dan mislukte het gietsel. Na het afkoelen van het metaal werd het nieuwe vat tevoorschijn gehaald door het uit de keramieken 'verpakking' te hakken. Bij dit gietprocédé gingen telkens weer zowel het originele model alsook de buitenwanden van de gietvorm verloren. Alle bronzen objecten uit de Shangen de Westelijke Zhou-tijd zijn dus unica. Voor de heersende elites van de vroege Bronstijd was het maken van honderdduizenden afzonderlijk geproduceerde vaten nog wel te doen, maar vanaf de $8^{e}$ eeuw v.Chr. was er om verschillende redenen een toenemende vraag naar een hoogwaardige bronsproductie. Een industrie gebaseerd op het vervaardigen van unica kon dit niet bijhouden. Ook de noodzaak om een zeer hoge en gelijkmatige kwaliteitsnorm te handhaven, dwong de bronsgieterijen al gauw tot de invoering van volledig nieuwe productiemethoden. Zo begon voor de bronsindustrie het tijdperk van de mechanisched reproductie. $_{\text {- }}$ 04/26/2023 11:21:14AM 
De meeste latere objecten in deze tentoonstelling zijn gemaakt met behulp van mechanisch reproduceerbare gietvormen. De gieterij die het succesvolst werkte met dit soort mal bevond zich nabij de huidige noordelijke stad Houma. Deze gieterij, die vanaf 1957 door archeologen is blootgelegd, werkte met motiefblokken: negatieve kleiafdrukken, die gemaakt zijn van een prototype dat het patroon in positieve vorm bevat - dus zoals dit er in brons uit komt te zien. Eén prototype gaat lang genoeg mee om er motiefblokken met hetzelfde patroon van te vervaardigen voor vele tientallen individuele objecten.

Dat de productiesnelheid van een gieterij toenam door deze mechanische reproductie behoeft geen betoog. Een ander groot voordeel van de in Houma toegepaste procédés was dat nu series identieke vaten of klokken konden worden vervaardigd. Veel objecten die in de late Bronstijd met deze techniek werden geproduceerd, waren bestemd voor rijke opdrachtgevers die van plan waren om ze specifiek als een set vaten, klokken of wapens te tonen. Status aan het hof werd steeds meer bepaald door, bijvoorbeeld, het totaal aan bronzen vaten van het type ding dat koningen, hertogen, markgraven en hun echtgenotes mochten gebruiken (en uiteindelijk in het graf mochten meenemen).

De vroegste bronzen vaten zijn sterk beïnvloed door Neolithisch aardewerken potten. Zo zijn de oudste objecten in deze tentoonstelling - en vele andere -, zoals de $27 \mathrm{~cm}$. hoge jia, gemodelleerd naar keramische vaten die op drie poten rustten (afb. 1). Langzamerhand maakten de bronzen vaten zich los van de invloed van het aardewerk. Het materiaal brons maakte nieuwe vormen bereikbaar. Anders dan in keramiek, waarin het buitengewoon moeilijk is om rechthoekige vormen te realiseren, konden in brons vierkante modellen worden uitgevoerd (afb. 2).

\section{Motieven}

Tijdens de Shang-periode was het aantal motieven dat in de decors werd gebruikt beperkt. Onder de terugkerende decoratiemotieven bevindt zich een aantal abstracte patronen, draken, monstermaskers en vogels. Sommige van deze wezens zijn fabeldieren. Een van de beroemdste Shang-motieven is het monstermasker. Dit patroon heet een taotie, naar een term die is opgetekend in teksten uit de $5^{\mathrm{e}}$ eeuw v.Chr. De meningen verschillen over de vraag of de taotie een bepaalde betekenis heeft. $\mathrm{Er}$ is wel gewezen op overeenkomsten met de monsters en fabeldieren in vroege mythen uit vele culturen. Mogelijk diende de taotie om ontzag in te boezemen, angst aan te jagen en macht te symboliseren.

Tegen het einde van de Shang-tijd leek het taotie-gebruik uit de gunst te zijn geraakt, en begonnen de ontwerpers meer met vogels en draken te experimenteren, mogelijk onder invloed van noordelijker volkeren. Uiteindelijk zou men in de loop van de Westelijke Zhou-dynastie afstand doen van bijna alle Shang bronskunst. De Zhou-vorm van de taotie werd bijvoorbeeld enorm vereenvoudigd en verdween niet veel later uit het zicht. Het enige motief van de Shang-ontwerpen dat door de hele Zhou-tijd heen is blijven bestaan, was de draak.

De overgang van Shang naar Zhou wat betreft visuele voorkeuren heeft misschien te maken gehad met veranderingen in de bronsindustrie, yan de $21: 14 \mathrm{Am}$ Zhou-tijd en met andere prioriteiten bij het gebruik van vaten tijdens rifueleaccess 

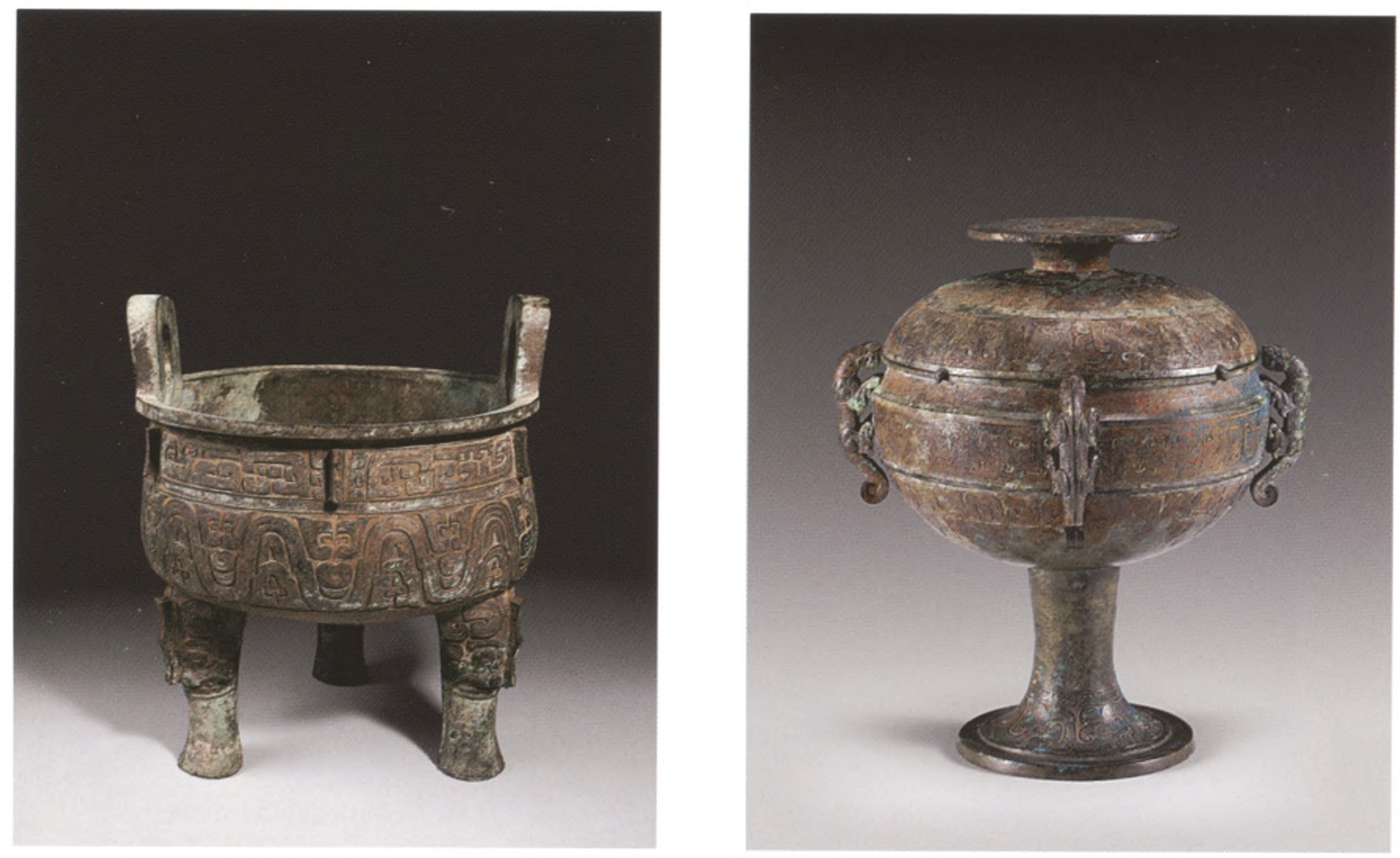

Afbeelding 3 (links) Kleine Ke ding (spijsvat). Koning Xiaorijk van de Westelijke Zhou (eind $10^{\mathrm{e}}$ eeuw v.Chr.), hoogte $56,5 \mathrm{~cm}$., doorsnede (mond) $49 \mathrm{~cm}$, cat. nr. 31 .

\section{Afbeelding 4}

Dou (spijsvat) met vier tijgers en verstrengelde drakenpatronen. Late Lente- en Herfsttijdperk (eerste helft van de $6^{e}$ eeuw - 476 v.Chr.), hoogte $26,4 \mathrm{~cm}$., breedte (buik) $18,6 \mathrm{~cm}$, cat. nr. 50. handelingen. Een groot aantal vattypes die in omloop waren geweest tijdens de Shang-periode werd niet meer vervaardigd door de bronsindustrie van de Westelijke Zhou, zoals de jia en de jue, en er verscheen een aantal nieuwe types, stuk voor stuk spijsvaten. Voedselvaten werden de centrale stukken in de bronzen serviezen.

Naarmate de Bronstijd afliep, decoreerden de gieters hun vaatwerk steeds vaker met inlegwerk van andere materialen, zoals goud, zilver, lak, steen of stras, dat ze combineerden met het aloude maar toch vrij ongebruikelijke turkoois, malachiet, glas, zuiver koper en vermoedelijk ook lood. Hiermee creëerden ze vlakversieringen die vaak overeenkwamen met die van de textiel-, keramiek- of lakindustrie.

\section{Teksten}

De vaten werden indertijd niet alleen voor decoratieve of praktische doeleinden gebruikt. Een belangrijke bron voor het vaststellen van de functic zijn de teksten op de bronzen voorwerpen zelf. Veel van de objecten - op de tentoonstelling de helft - bevatten namelijk inscripties in vroege vormen van het Chinese schrift. Deze teksten onthullen vaak waarom de vaten en klokken zijn gemaakt en hoe ze werden gebruikt. Dit gebruik veranderde met de tijd, en dus ook de reden waarom men ze liet voorzien van teksten. Alle inscripties waren in principe verslagen, gericht aan de voorouders, en de vaten waren de media waarmee deze rapporten werden gecommuniceerd. Centraal in het religieuze leven stond de vooroudercultus. Offers aan voorouders waren bedoeld om de dode voorvaderen terug te roepen in de tegenwoordigheid van de levenden. Bovendien waren de afstammelingen verplicht om hun eigen verrichtingen te rapporteren, en daarmee hun 23 11:21:14AM voorouders eer te bewijzen. Deze gerapporteerde wapenfeiten warenizonderaccess 

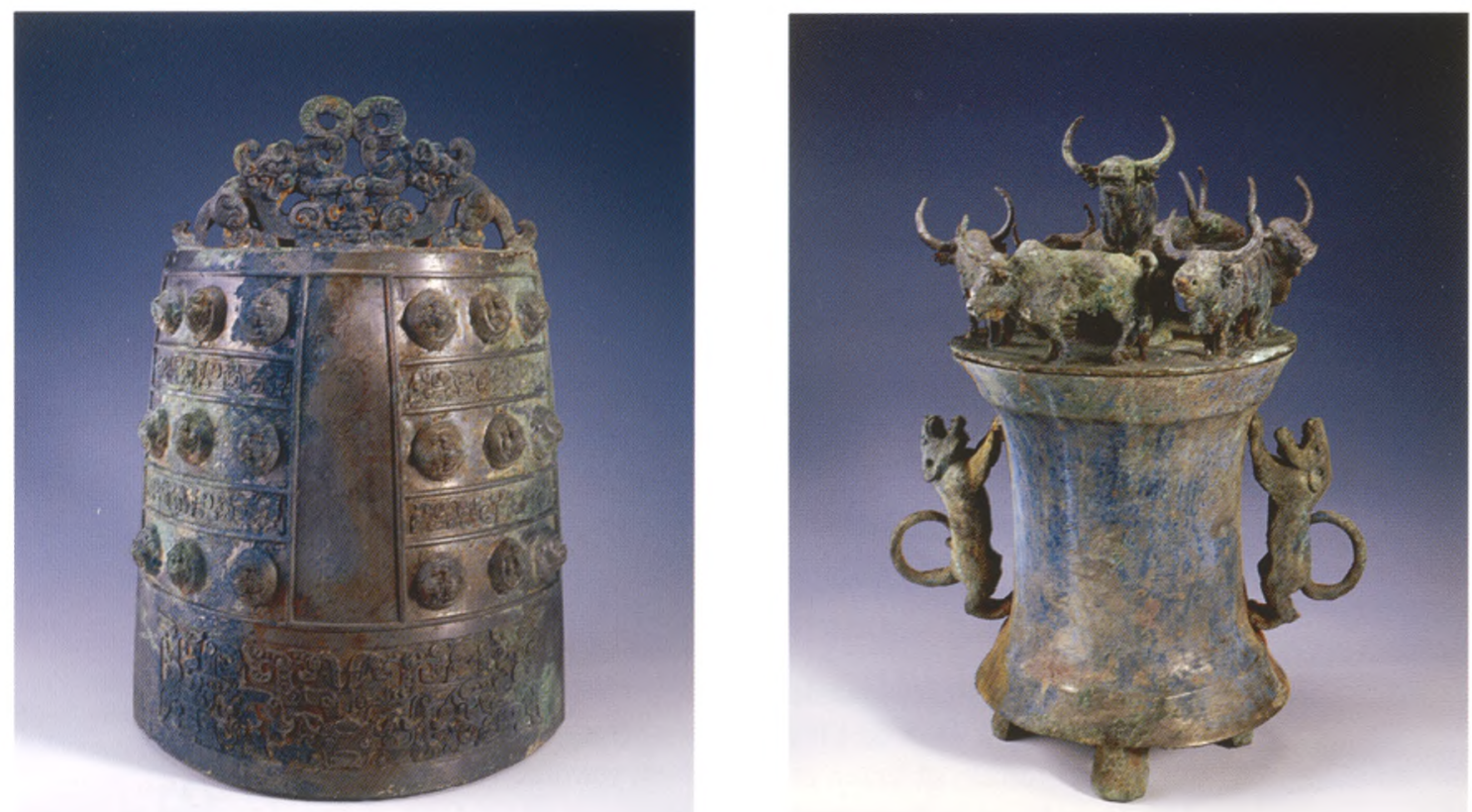

Afbeelding 5 (links) Bo (klok) met verstrengeld drakenpatroon. Late Lente- en Herfsttijdperk (eerste helft van de $6^{\text {e }}$ eeuw - 476 v.Chr.), hoogte $43,7 \mathrm{~cm}$., breedte (buik) 31,6 cm, cat. nr. 53.

Afbeelding 6 Vat voor kaurischelpen met zeven jakken. Westelijke Han-periode (206 v.Chr. - 8 n.Chr.), hoogte $45,5 \mathrm{~cm}$., breedte $36 \mathrm{~cm}$, cat. nr. 61. uitzondering aan de heerser bewezen diensten, die in reactie daarop titels, promoties en geschenken ter beloning uitreikte. Al deze voorspoed moest worden gemeld aan de stamvaderen.

Sommige van de oudst overgeleverde teksten in China, daterend uit de late Westelijke Zhou, geven meer bijzonderheden over de totstandkoming van de communicatie tussen levenden en doden. Uitgebreide feestmalen werden in de bronzen spijs- en drankvaten bereid en opgediend ten behoeve van zowel voorouders als nazaten. De dode voorouders werden opgeroepen om aanwezig te zijn in de lichamen van 'plaatsvervangers', die uit de afstammelingen geselecteerde geestenmediums waren. Hierbij hadden de vaten met inscripties de functie het rapport van de nazaten door te geven. De plaatsvervangers van de doden - de voorouders zelf in dit geloofssysteem - namen het voedsel en de drank die in aanraking waren geweest met de woorden van het verslag tot zich.

\section{Voorouders}

Het cruciale onderdeel van een bronsinscriptie was de naam van de voorouder, en dit ene karakter - of vaak niet te lezen schriftteken - kan ook de enige aanwezige tekst zijn. De voorouderlijke naam is tevens de titel waarmee men lange tijd zo handig naar de vaten met hun inscripties verwees. $Z 0$ is een object dat als Zhu lei wordt aangeduid, een vat van het lei-type gewijd aan een voorouder die Zhu heet. Iets informatiever is de benaming Zhui Fu Gui zun, dat een vat omschrijft van het type zun, gewijd aan Voorvader (Fu) Zhui aan wie men elke tiende (Gui) dag moet offeren.

Naarmate de eeuwen verstreken, werden de inscripties langer. Een van de beroemdste vaten van de Westelijke Zhou op deze tentoonstelling is de Kleine Ke ding met aan de binnenzijde een tekst van 72 karakters inia free access 
kolommen geordend (afb. 3). Op dit vat beschrijft Ke de plichten betreffende een voorouder die zelf grote eer had verworven in dienst van de Zhoudynastie vier regeerperiodes daarvoor. De tekst eindigt met: 'Ke hoopt dat zijn zonen en kleinzonen dit [vat] altijd zullen blijven koesteren en gebruiken, tienduizend jaar lang, tijdens de voorouderlijke festiviteiten.' Deze vaste formule komt in duizenden inscripties voor.

In de laatste eeuwen van de Bronstijd pasten de uitvoerige biografische verslagen van bestuursdeelname, diplomatie en oorlogsvoering nauwelijks nog op het oppervlak van een enkel vat. Daarom besloten de opdrachtgevers van bronzen vaatwerk steeds vaker om de inscripties van de binnen- naar de buitenkant van een vat te verplaatsen. Deze inscripties aan de buitenzijde konden zo prominent aanwezig zijn, dat ze zich niet zozeer tot dode voorouders richtten als wel tot de levenden.

\section{Verzamelen}

In de loop van de tijd werden al deze artefacten antiquiteiten, gewild onder collectioneurs. $\mathrm{Al}$ in de $11^{\mathrm{e}}$ eeuw (Song-dynastie) was het verzamelen van antieke bronzen objecten een bezigheid geworden waarin men onderling wedijverde, en in deze eeuw verschenen ook de vroegste verzamelaarcatalogi. De oudst bewaard gebleven verhandeling over gebruiksvoorwerpen uit de Bronstijd is Illustraties ter onderzoek van het verleden (Kaogu tu) van Lü Dalin, een enthousiaste verzamelaar en historicus tijdens de Noordelijke Song (9601127), in het jaar 1092.

De bronzen fungeerden inmiddels als het tastbare bewijs voor de oude oorsprong van de Chinese beschaving. In de afgelopen honderden jaren zijn de kunst van de Shang- en de Zhou-tijd enthousiast gekopieerd in andere materialen en opgenomen in nieuwe artistieke praktijken. Het in 1996 heropende Museum van Shanghai, gebouwd in de vorm van een bronzen ding, is een van de meest recente voorbeelden waaruit blijkt dat de Bronstijd in China nog altijd een levendige bron van inspiratie vormt.

Deze tekst is een verkorte bewerking van het essay dat Oliver Moore voor de catalogus bij de tentoonstelling schreef.

- De tentoonstelling 'Antieke bronzen; meesterwerken uit het Shanghai Museum' is onderdeel van het project 'Go China! Assen-Groningen'.

Van 2 februari $t / m 28$ september 2008

Groninger Museum

Museumeiland 1

$9711 \mathrm{ME}$ Groningen

www.groningermuseum.nl 